\title{
Prática e coeficiente na produção de documentos: uma ação sustentável
}

Breno Rolindo Lara Moreira

Estudante do Curso de Engenharia Ambiental (Universidade Federal de Minas Gerais).Estagiário do Programa Sustentabilidade da Câmara Municipal de Belo Horizonte

Adriana Fileto Couto e Silva de Oliveira

Gestora do Programa erastentabilidade
Economista, Mestre em $\begin{array}{r}\text { Sudministração } \\ \text { (CEPEAD/UGMG) }\end{array}$

Janete Fernandes Silva

Professora do Departamento de Biblioteconomia da Universidade Federal de Mato Grosso

Apesar das questões relativas à sustentabilidade e ecoeficiência estarem na ordem do dia das organizações, muitos gestores enfrentam dificuldades ao adotarem práticas ecoeficientes, por conta do descrédito de colaboradores. Este artigo realizou um estudo empírico pioneiro e comprovou que a Ecofont contribui significativamente para a economia de recursos (naturais e materiais), além de reduzir a emissão de dióxido de carbono. Optou-se pelo estudo de caso na Câmara Municipal de Belo Horizonte, porque a organização é responsável por um volume significativo de impressão de documentos. Foram utilizados dados primários, cálculos, testes e softwares, como Word 2003 e APFILL.

Palavras-chave: Ecofont; Produção de documentos; Sustentabilidade; Processo administrativo.

\section{Practice eco-efficient production of documents: a sustainable action}

Although the issues of sustainability and eco-efficiency are on the agenda of organizations, many managers face difficulties in adopting eco-efficient practices on behalf of employees' disbelief. This article conducted a pioneering empirical research and discover the Ecofont contributes 
significantly to the economy of resources (natural and material) and also reduce the emission of carbon dioxide. We chose the Municipality of Belo Horizonte as the case of study because the organization is responsible for a significant volume of printing documents. We used primary data, calculations and testing software like Word 2003 and APFill.

Keywords: Ecofont; Document production; Sustainability; Administrative proceedings.

Recebido em 06. 05.2013 Aceito em 10.07.2013

\section{Introdução}

As questões relativas à sustentabilidade tornam-se cada vez mais importantes para a sociedade. Segundo a ONG WWF (2010), atualmente se consome $50 \%$ mais do que a capacidade de renovação do planeta, seja em ar limpo, água potável, terra ou recursos naturais e agrícolas. Isso significa que, até 2030, a humanidade necessitará da capacidade de dois planetas Terra para absorver os resíduos de dióxido de carbono $\left(\mathrm{CO}_{2}\right)$ e manter o consumo de recursos naturais. O resultado desse consumo excessivo e desenfreado é a perda da biodiversidade, que chegou a $30 \%$, nos últimos 40 anos, em todo o planeta.

De acordo com o estudo realizado pela PricewaterhouseCoopers (2012, p. 2), a limitação do aquecimento global em $2^{\circ} \mathrm{C}$ requer uma taxa de descarbonização da economia equivalente a 5,1\% ao ano, até 2050. No entanto, essa limitação do aquecimento global está comprometida, pois seria necessário que tal taxa aumentasse em mais de seis vezes em relação à taxa atual de $0,7 \%$, estimada em 2011 . E os números revelam o decréscimo desse indicador, pois entre o período 2000-2011, o percentual foi de 0,8, passando em 2011 para 0,7.

Tendo em vista esse cenário preocupante, que conta com as organizações como umas das principais responsáveis pelas alterações ocorridas no ecossistema, é imprescindível a adoção de sistemas organizacionais de gestão sustentáveis. Segundo Sukhdev (2012), no mundo, dois terços do PIB e quase dois quartos da ocupação da mão de obra cabem às empresas. Para se ter ideia do impacto ambiental de uma empresa, cita-se como exemplo a PUMA. Essa empresa, que atua no segmento esportivo, obteve, em 2010, um lucro de 220 milhões de euros e custos ambientais não pagos no valor de 145 milhões de euros. Esses números revelam que os danos ambientais gerados por empresas são significativos, mas como muitas vezes não são cobrados, o ecossistema sofre consequências desastrosas (SUKHDEV, 2012). De acordo com Abramovay (2012), o traço central das atividades corporativas dominantes a partir de 1920 (em oposição ao que deve ocorrer com a 
"Corporação 2020"), é a obtenção de ganhos cada vez mais apoiados em perdas, tanto para os ecossistemas como para o próprio mundo social.

Uma maneira de as organizações atingirem a tão almejada sustentabilidade é implantando variáveis ambientais, como a gestão ambiental de processos e produtos. A gestão ambiental de processos visa, através de tecnologias ambientais, melhores resultados, com destaque para a Produção Mais Limpa. Alinhada a essa, encontra-se a gestão de produtos, que avalia o ciclo de vida dos produtos, o seu impacto no meio ambiente, que se inicia com a matéria-prima utilizada, considerando o seu transporte, o modo de fabricação, a utilização e o descarte do produto final (RITZMAN; KRAJEWSKI, 2004; OLIVEIRA, 2007; GAITHER; FRAZIER, 2007; SLACK; CHAMBERS; JOHNSTON, 2009; DIAS, 2011). O uso de métodos de gestão ambiental faz parte do processo de desenvolvimento e inovação de produtos e permite melhores resultados econômicos por parte da organização. A falta de incorporação, no planejamento estratégico, de ações corretivas e preventivas que minimizem os danos causados ao meio ambiente, tem contribuído com as modificações desastrosas ocorridas no ecossistema mundial. Essas modificações geram impactos negativos como contaminações ambientais e extinções na fauna terrestre e marinha. Segundo Savitz e Weber (2007, p. 6) apud Munck (2010, p. 4),

a sustentabilidade é hoje, princípio fundamental da gestão inteligente, algo muito fácil de ignorar ou assumir como inevitável, num mundo em que o resultado financeiro geralmente é visto como a única medida de sucesso.

Corroborando com os autores, pode-se dizer que a ecoeficiência torna-se estratégica para as organizações, quando alinhada às questões sustentáveis. A ecoeficiência é compreendida como um processo de produção no qual se produz mais com menos, ou seja, reduzindo o consumo de materiais e energia, a geração de resíduos e os custos operacionais, respeitando-se os objetivos ambientais (DIAS, 2011). A intenção da ecoeficiência é a preservação ambiental e a utilização cuidadosa da base biofísica, ambiental da economia e do uso adequado e cauteloso dos recursos naturais (MELO NETO; BRENNAND, 2004). Caminhando nessa direção, de acordo com Cavalcanti (s. d., p. 17) apud Melo Neto e Brennand (2004, p. 97),

a sustentabilidade significa uma orientação das ações públicas motivada pelo reconhecimento da limitação ecológica fundamental de recursos (matéria e energia em última análise), sem os quais nenhuma atividade humana pode ser realizada.

É a sustentabilidade centrada no alcance simultâneo de resultados financeiros, sociais e ambientais. 
É importante ressaltar que as práticas sustentáveis são urgentes e cabem a todos: indivíduos, organizações privadas e do terceiro setor e poder público. Neste artigo, buscou-se destacar a importância do poder público na adoção de práticas sustentáveis, devido a sua expressiva participação no mercado como empregador. O poder público, ao incorporar práticas de gestão sustentáveis, é capaz de criar um verdadeiro círculo virtuoso em prol da sustentabilidade. Em 2009, o número de servidores públicos correspondia a $12 \%$ do total de empregados no país, podendo mobilizar milhões de pessoas em prol das práticas sustentáveis (ESTADÃO, 2009). Constata-se, assim, o imenso potencial do poder público em promover a ecoeficiência, pois, além de influenciar seus servidores, ele também desempenha um papel crucial na indução dos fornecedores a adotarem práticas sustentáveis.

Entretanto, embora a adoção da ecoeficiência por organizações públicas se constitua em uma importante prática sustentável, muitas vezes os servidores costumam questionar a eficácia de tais práticas e denominá-las como modismos. O Conselho Empresarial para 0 Desenvolvimento Sustentável recomenda a realização de pesquisas, a fim de identificar oportunidades de redução na intensidade de consumo de materiais e energia que revertam em benefícios para as organizações. Esse Conselho também aponta a reorientação dos processos produtivos como uma das áreas possíveis para se melhorar a ecoeficiência (DIAS, 2011).

No intuito de contribuir para o debate das práticas ecoeficientes nas organizações, este artigo buscou realizar uma pesquisa para avaliar se a Ecofont é ecoeficiente no que se refere à economia de recursos naturais (água), recursos materiais (papel, toner, cartucho) e recursos financeiros, além de diminuir a emissão de dióxido de carbono $\left(\mathrm{CO}_{2}\right)$. Uma vez comprovada a ecoeficiência, seria mais fácil vencer a barreira do descrédito dos colaboradores em relação ao uso da Ecofont e os resultados seriam apresentados aos gestores da organização pesquisada na tentativa de implantar o novo tipo de fonte tipográfica. Além disso, esta pesquisa também poderia ser utilizada por outras organizações públicas e privadas, que desejarem adotar práticas sustentáveis. Optou-se pelo estudo de caso na Câmara Municipal de Belo Horizonte (CMBH), porque se trata de uma organização pública responsável por um volume significativo de impressão de documentos.

Previamente ao desenvolvimento desta pesquisa, realizou-se um levantamento, na literatura científica, na tentativa de encontrar estudos que abordassem a relação entre as fontes tipográficas e a sustentabilidade, como, também, os tipos de fontes sustentáveis e as características de cada um que resultaram em práticas ecoeficientes. Ainda que uma vasta pesquisa tenha sido realizada, notou-se uma grande ausência de estudos sobre o assunto, apenas menções isoladas sobre alguma fonte tipográfica em especial, não havendo nenhuma publicação que incorporasse esses valores.

Além dos dados divulgados pelas próprias empresas desenvolvedoras dos tipos de fontes, poucas informações foram obtidas 
através da pesquisa realizada. Dessas poucas pesquisas encontradas, destacam-se o estudo Printing Costs: Does Font Choice Make a Difference? , publicada pela empresa Printer.com e o Sustainable by Design: An Investigation into Ecologically Friendly Typography desenvolvido pelo Rochester Institute of Technology (RIT). O estudo desenvolvido pela Advocacia Geral da União (AGU) realizou testes semelhantes, publicando os resultados, entretanto a AGU não explicitou sua respectiva metodologia. Visando obter informações sobre as metodologias utilizadas nos estudos, fizeram-se contatos por e-mail com as instituições, mas não houve respostas. Diante da escassez de informações e de métodos em fontes científicas, este artigo é pioneiro por explicitar, de forma minuciosa, não só os resultados, como toda a metodologia definida e empregada. O que permitiu ampliar o foco de análise, abrangendo o impacto ambiental direto e indireto advindo do uso de diferentes fontes tipográficas, o que reforça o caráter inovador dos dados apresentados. Portanto, tornou-se necessária a realização de uma pesquisa detalhada para avaliar se o processo de impressão de folhas através do uso Ecofont é realmente ecoeficiente. Além disso, foi possível mensurar a redução no consumo de recursos naturais (água), financeiros e materiais (cartucho, toner, papel) e estimar a diminuição da emissão de $\mathrm{CO}_{2}$ advindo do uso da Ecofont na Câmara Municipal de Belo Horizonte $(\mathrm{CMBH})$, que é responsável pela aquisição de mais de um milhão de folhas A4 por ano.

\section{Metodologia}

Neste tópico, será descrito o posicionamento metodológico que permitiu a construção deste artigo. Optou-se pelo estudo de caso, por esse permitir a investigação empírica de um fenômeno dentro de um contexto (YIN, 2005). No que se referem às fontes de dados, foram utilizados dados primários da Câmara Municipal de Belo Horizonte (CMBH) relacionados ao consumo de papel, toner e tinta. Como dados secundários, utilizaram-se os resultados da pesquisa publicada no site da empresa Printer.com. Foram realizados cálculos, testes e utilizados softwares como o Word 2003 e o APFILL.

Como ponto inicial da pesquisa, utilizaram-se fontes potencialmente econômicas no consumo de cartuchos de tinta e toner e que apresentassem um estilo limpo e formas compactas, resultando em um menor uso de folhas de papel para impressão. Após uma pesquisa prévia, constatou-se que os tipos de fontes mais apropriadas para o estudo foram Century Gothic, Ecofont Vera Sans e Times New Roman.

A fim de se possibilitar a criação de indicadores, tomou-se como papel padrão a folha A4, de dimensões $21 \mathrm{~cm}$ de largura e 29,7 cm de comprimento e a configuração default do Word 2003 para página e fonte. Para os indicadores, definiu-se como unidade comum de fonte a letra "a" minúscula, de modo que, independentemente do tamanho escolhido, as três fontes possuíssem o mesmo tamanho espacial ou o mais próximo possível. Quanto às margens do papel, utilizaram-se três centímetros para 
as margens esquerda e direita e dois ponto cinco centímetros para as margens superior e inferior. O espaçamento entre linhas é simples. Quanto ao espaçamento entre os caracteres, tem-se: dimensão $100 \%$, espaçamento 0 e posição 0 .

Já os dados levantados para cada fonte foram construídos por meio de testes realizados na própria organização. Esse caminho permitiu não só um maior controle dos processos geradores, como a flexibilidade dos resultados obtidos, podendo-se alterar qualquer teste, de acordo com a demanda necessária, algo extremamente difícil ao se fazer uso de valores secundários.

O levantamento dos dados ocorreu no ano de 2011 , em que o consumo de unidade de papel A4 foi de 2.379 pacotes, tomando-se o valor de referência o pacote de 500 folhas com preço médio de $\mathrm{R} \$ 8,26$ e totalizando o valor de $\mathrm{R} \$ 19.373,87$. Quanto ao consumo de cartuchos de tinta e toner, utilizou-se 311 unidades, com o preço médio de R\$274,23, somando um valor de $\mathrm{R} \$ 85.286,55$. O total geral do consumo anual nesse ano foi de $\mathrm{R} \$ 104.660,42$.

Convém salientar que cada fonte em estudo possui um espaço ocupado pela unidade de fonte peculiar, de modo que tamanhos iguais de diferentes tipos não necessariamente ocupam a mesma área, consequentemente, acarretando gastos distintos com papel para impressão. A fim de se tornar possível uma análise direta entre cada uma delas, procurou-se desenvolver indicadores que funcionassem de forma complementar entre si, mensurando não só a área específica de cada fonte como a quantidade de toner/tinta necessária para a sua impressão. Para tal, tornou-se necessário a definição dos seguintes indicadores:

a) área utilizável da folha padrão $(K)$ : é o valor da constante $K$ que corresponde à área em centímetros quadrados do espaço físico disponível da folha padrão definida $A 4$. O valor de $\mathrm{K}$ é assim calculado:

$\mathrm{K}=$ (Área total da folha padrão) - (Área utilizada como margem da folha padrão);

número de caracteres para preenchimento total da folha (NT): revela o número de caracteres "a" digitados em série e sem espaçamentos necessários para a utilização plena da folha. Para o teste, abriu-se um documento em branco no Word 2003 e escolheu a fonte de estudo, digitando-se a unidade de fonte de forma contínua e sem interrupções, de modo a, conforme mencionado anteriormente, ocupar todo o espaço disponível do papel. Após esse processo, fez-se uso da ferramenta do próprio Word denominada "Contar palavras" sendo possível, assim, se obter o número exato de caracteres presentes ali. Quanto maior o valor de NT, maior é o número de letras cabíveis de serem digitadas no espaço $\mathrm{K} \mathrm{e}$, portanto, menor a área ocupada por cada unidade; 
b) espaço de preenchimento por unidade de fonte (EU): mensura a área do quadrilátero ${ }^{1}$ em que o caractere "a" de uma determinada fonte está inserido. A distribuição de cada fonte dentro do quadrilátero que a delimita é peculiar, dependendo do estilo de letra em questão e não seguindo algum padrão exclusivo. Na Figura 1 , percebe-se facilmente esse fato.

Figura 1 - Comparação entre as fontes Times New Roman e a Ecofont Vera Sans de mesmo tamanho

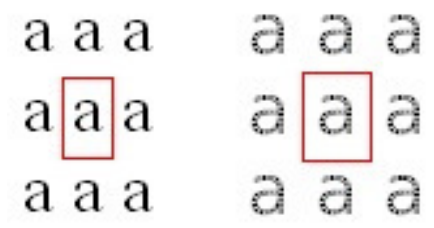

Fonte: Dados da pesquisa.

Assim, calculou-se o indicador Espaço de Preenchimento (EU) por unidade de fonte, dado naturalmente em $\mathrm{cm}^{2}$ :

$\mathrm{EU}=\mathrm{K} / \mathrm{NT}$

No qual K é a constante denominada Área utilizável da folha padrão, enquanto que o NT é o valor do indicador Número de caracteres para preenchimento total da folha; e

Taxa de preenchimento (TP): se o EU está diretamente relacionado ao consumo de folhas para impressão, o indicador taxa de preenchimento (TP), por sua vez, expressa de forma indireta o consumo de tinta/toner que cada fonte requer. $O$ método é simples, tomando-se um texto fixo escrito na fonte e escala desejada para análise, calcula-se a relação entre a área total branca e preta, no caso aquela ocupada pelos caracteres. Dessa forma, conclui-se que quão maior for o valor de TP, maior será o uso de tinta/toner. Ainda que de fácil equacionamento, TP é de difícil obtenção, uma vez que requer o valor exato tanto da área branca da folha como da ocupada por caracteres. Dessa forma, optou-se pela utilização de um software denominado Apfill, desenvolvido pela empresa Avpsoft justamente com esse objetivo. O Apfill é comercializado em dois tipos: o profissional, que apresenta mais funções, e o standart. Neste estudo, fez-se uso da versão Trial.

1 A escolha da expressão "quadrilátero" ocorreu pelo fato de que não necessariamente a área que engloba a unidade de fonte provém de um quadrado. As dimensões da figura dependem do tipo de fonte e do estilo de cada uma, sendo que, no exemplo no qual se usa a Century Gothic, é evidente essa discrepância. Facilmente se observa um maior alongamento vertical da figura delimitante, todavia, esse padrão pode se diferir para os demais tipos. 
Em linhas gerais, o programa "lê" um arquivo e o divide em uma determinada quantidade de quadrados e literalmente conta aqueles preenchidos por alguma tonalidade, realizando, assim, o cálculo de preenchimento, tanto para arquivos em preto e branco como para coloridos - dentre as formas disponíveis de realizar tal medição pelo programa, escolheu-se a mais acurada para o tipo preto e branco, a " $R G B$ and $B / W$ Coverage ratio (PDF, PS)". Metodologia semelhante é efetuada pelo estudo do RIT, Sustainable by Design: An Investigation into Ecologically Friendly Typography, sendo uma investigação sobre tipografia ecologicamente correta, que, por sua vez, faz uso do programa Photoshop para efetuar essa contagem.

Todavia, o software não é capaz de desenvolver tal contagem a partir do documento gerado pelo Word, sendo necessário o uso de uma segunda ferramenta para realizar a transição do arquivo para o tipo PDF. No caso, foi escolhido o programa PrimoPDF, desenvolvido pela empresa NitroPdf, que realiza essa conversão.

Para os testes da Taxa de Preenchimento, utilizou-se uma passagem de um livro de Saramago (2009) e foram escolhidas a escalas 10, 11 e 12 de cada uma das fontes em análise, de modo a ser possível a comparação do valor de TP entre as três. Dessa forma, tendo disponíveis os valores de TP e EU, que conjuntamente englobam os consumos de cartuchos para impressora e papel, é possível uma indicação de qual a fonte mais econômica do ponto de vista não só financeiro como ambiental.

Utilizou-se também como dado de consulta uma pesquisa desenvolvida pela empresa Printer.com, em 2009, denominada Printing Costs: Does Font Choice Make a Difference?, na qual a mesma compara diversos tipos de fontes em escalas distintas por meio do software Apfill. Ainda que a metodologia utilizada seja distinta desta apresentada aqui, os valores de preenchimento - coverage ratio -, obtidos pela empresa, dão uma grande ideia de como cada fonte se comporta quanto ao consumo de toner/tinta. Esse fato, aliado aos comportamentos percebidos posteriormente nessa análise, permitirão uma comparação entre os estudos, de modo a se esperar que ambos se corroborem. Para uma melhor compreensão, apresentam-se resultados dessa pesquisa, que foram adaptados pelos autores deste estudo. Foram selecionadas três fontes como a Century Gothic, de tamanho 10 e que ocupa um preenchimento de 3,45\% da folha; seguida da Ecofont Vera Sans, de tamanho 10 e com preenchimento 3,47\%; e, por última, a Times New Roman, de tamanho 11 e preenchimento 3, 54\%.

Os valores de preenchimento obtidos pelo site colocam a Century Gothic como a mais econômica quanto ao consumo de tinta, sendo seguida de perto pela Ecofont Vera Sans. Logo após, com um acréscimo de $0,07 \%$ do valor da Taxa de Preenchimento a mais que a anterior, figura a Times New Roman 11, confirmando a escolha dos três tipos de fontes para a realização desse estudo. Importante ressaltar que os testes 
realizados na Ecofont Vera Sans e Century Gothic pela empresa são executados na mesma escala de letra, diferindo-se para o tamanho 11 apenas nas medições da Times New Roman. Conforme demonstrado, tipos de fontes diversos apresentam valores de NT e EU peculiares.

Essas quantias, ainda que diferentes das aqui produzidas, chamam a atenção para uma tendência dos resultados, no qual se aloca a Century Gothic como fonte de menor consumo de toner/tinta. Esse comportamento, mesmo que proveniente de uma metodologia distinta, também é esperado para os números de TP posteriormente levantados neste texto, de modo a ratificar a iniciativa da empresa Printer.com.

\section{Análise dos resultados obtidos para cada tipo de fonte}

Buscando-se o maior controle possível dos dados a serem utilizados neste artigo, evitou-se ao máximo recorrer a fontes secundárias, controle esse realizado com a finalidade de maximizar a confiabilidade final do trabalho desenvolvido. Dessa forma, nesta seção, serão apresentados os resultados do estudo das fontes para os indicadores desenvolvidos.

A escolha pela fonte Times New Roman justifica-se, como parâmetro, devido a sua grande popularidade no Brasil. Para os testes, fez-se uso da TR, nos tamanhos 10, 11 e 12, mesmo buscando-se uma fonte alternativa com uma área de ocupação similar a 12, tendo em vista sua excelente legibilidade e estilo. Os valores dos demais tamanhos serviram apenas como apontadores da tendência, facilitando 0 entendimento de como os indicadores variam em consequência da alteração da escala da fonte.

Sabe-se que escalas inferiores a 12 para a Times New Roman, afetam gradativamente a legibilidade do que está digitado. Isso se deve ao fato da própria TR possuir uma grande compatibilidade natural, ou seja, cada caractere é escrito bem próximo do outro, sendo indicada pelos seus altos valores de NT e baixos de EU, conforme pode ser verificado na Tabela 1.

Tabela 1 - Resultado dos indicadores desenvolvidos

\begin{tabular}{ccccccc}
\hline Indicador & \multicolumn{2}{c}{$\begin{array}{c}\text { Times New Roman } \\
\text { Tamanho } \\
\text { da fonte }\end{array}$} & Valor & $\begin{array}{c}\text { Century Gothic } \\
\text { Tamanho } \\
\text { da fonte }\end{array}$ & Valor & \multicolumn{2}{c}{$\begin{array}{c}\text { Ecofont Vera Sans } \\
\text { Tamanho } \\
\text { da fonte }\end{array}$} & Valor \\
\hline \hline \multirow{2}{*}{ NT } & 11 & 5700 & 10 & 3534 & 10 & 4140 \\
& 12 & 4785 & 11 & 2856 & 11 & 3402 \\
EU & 12 & 3950 & 12 & 2397 & 12 & 2850 \\
& 10 & 0,065 & 10 & 0,1048 & 10 & 0,0895 \\
& 11 & 0,0774 & 11 & 0,1297 & 11 & 0,1089 \\
TP & 12 & 0,0938 & 12 & 0,1546 & 12 & 0,13 \\
& 10 & 2,1 & 10 & 2,55 & 10 & 2,59 \\
\end{tabular}

Fonte: Dados da pesquisa.

Nota: ${ }^{a}$ Valores de EU são dados em $\mathrm{cm}^{2}$. 
A Tabela 1 demonstra que a escolha da Century Gothic como parâmetro para este estudo se justifica, tendo em vista o seu baixo consumo de toner e tinta, quando comparada com as demais.

Verifica-se que os valores de NT da CG são baixos quando comparados a outras fontes, como a Times New Roman, indicando que embora a mesma seja econômica no que refere ao uso de cartuchos de toner, ela resulta em um maior gasto de papel para impressão. O valor de NT obtido para a Century Gothic, em tamanho 10, sendo este o maior número obtido para os três tamanhos, ainda assim é inferior em mais de 400 unidades que o mesmo para a TR 12. Tal paradoxo, os valores baixos de NT - e, consequentemente, grandes de EU - juntamente com a baixa taxa de preenchimento, são resultados dos maiores espaços entre os caracteres, assim como o seu estilo alongado.

Importante salientar, também, que, para mérito comparativo, teria que se utilizar a CG tamanho 10, quiçá 9, a fim de se obter um valor de NT próximo de 3950 - o valor da Times New Roman 12 -, entretanto, ambas as dimensões apresentam pouco legibilidade, conforme demonstrado no seguinte exemplo para o tamanho 10:

"Estudo desenvolvido no objetivo de demonstrar a viabilidade da alteração da fonte padrão por uma alternativa".

Dessa forma, preferiu-se efetuar a análise tendo em vista o tamanho mínimo 11, visando uma menor resistência dos funcionários da $\mathrm{CMBH}$.

O design alternativo da Ecofont Vera Sans se constitui em caracteres com pequenos furos internos, que, segundo a SPRANQ Utretcht, empresa criadora da fonte, possibilitam a redução de $28 \%$ no consumo de tinta ou toner.

Fácil visualizar a olho nu que, a partir do tamanho 20, começa-se perceber a existência de furos, entretanto, para escalas menores, essa peculiaridade se torna de difícil percepção, não afetando a legibilidade do texto. O grande entrave desse software é o fato de ser pago, entretanto a variante EV em análise é distribuída de forma gratuita para o uso, podendo ser utilizada por tempo indeterminado.

Comparando-se os valores da Ecofont Vera Sans com a Times New, tanto os valores de EU para EV 10 como EV 11 são bem próximos ao de TR 12, diferindo-se de apenas poucas unidades. Conjuntamente, os dois tipos de fontes são construídos com um estilo semelhante, resultando em uma fácil visualização e legibilidade. Dessa forma, com uma análise primária, ambas as escalas da Ecofont Vera Sans acabariam por desempenhar, de forma satisfatória, o seu papel, substituindo a Times New Roman internamente na $\mathrm{CMBH}$, entretanto, optou-se pela EV 10, decorrente do seu menor valor de TP. 


\section{Análise geral do estudo empírico}

Neste item do artigo, será realizada uma análise comparativa entre as três fontes a Times New Roman, Cetury Gothic e Ecofont Vera Sans, a fim de avaliar o potencial de economia tanto de cartuchos de toner e tinta quanto de folhas de papel advindas da utilização de cada tipo de fonte.

\subsection{Consumo de cartuchos de toner e tinta}

Para análise do quão dispendioso se mostra certo tipo de fonte, é esperada uma correlação entre os valores de Taxa de Preenchimento de cada uma em particular, tendo em vista que menores valores de TP repercutem em uma maior economia. Novamente, a Ecofont Vera Sans 10 apresenta um melhor índice (2,59\%), inferior ao se comparar à TR 12 e CG $11,2,96 \%$ e 3,03\% respectivamente. Essa diferença resultaria em redução de $12,5 \%$ do consumo de cartuchos de toner e tinta, caso se optasse pelo uso da EV 10 em detrimento da TR 12. Veja dados na Tabela 2.

Tabela 2 - Valores dos indicadores para as fontes em seus tamanhos escolhidos para análise

\begin{tabular}{cccccc}
\hline Tipo de fonte & Tamanho & NT & EU $^{\text {a }}$ & TP & Exemplo \\
\hline Times New Roman & 12 & 3950 & 0,0938 & $2,96 \%$ & Impressão \\
Ecofont Vera Sans & 10 & 4140 & 0,0895 & $2,59 \%$ & Impressão \\
Century Gothic & 11 & 2856 & 0,1297 & $3,03 \%$ & Impressão \\
\hline
\end{tabular}

Fonte: Dados da pesquisa.

Nota: ${ }^{a}$ Valores de EU são dados em $\mathrm{cm}^{2}$.

Conforme revela a Tabela 3, o gasto anual com cartuchos, de acordo com cada fonte, é o seguinte: TR 12 de $R \$ 85.288,55$ e a adoção da Ecofont Vera Sans implicaria em um gasto anual de apenas $\mathrm{R} \$ 74.627,48$, o que possibilita uma economia $12,5 \%$, correspondendo a $R \$ 10.665,00$.

Tabela 3 - Resultados anuais para consumo de cartuchos de tinta e toner para as fontes estudadas

\begin{tabular}{cccc}
\hline Tipo de fonte e tamanho & TP & Custo (R\$) & Variação \\
\hline \hline Ecofont Vera Sans 10 & $2,59 \%$ & $74.627,48$ & $-12,50 \%$ \\
Century Gothic 11 & $3,03 \%$ & $87.301,36$ & $2,36 \%$ \\
Times New Roman 12 & $2,96 \%$ & $85.288,55$ & $0 \%$ \\
\hline
\end{tabular}

Fonte: Dados da pesquisa.

Além disso, a fabricação de um novo cartucho de toner requer o uso de 5 litros de petróleo, demorando mais de 100 anos, em média, quando descartados, para serem absorvidos pela natureza (NAGANO, 2000). Ao se analisar os 311 cartuchos utilizados anualmente, traduzidos em 1555 litros, a redução de 12,5\%, conforme observado na Tabela 3, implicaria 
em aproximadamente 38 cartuchos a menos e, consequentemente, um alívio para o meio ambiente de cerca de 190 litros de petróleo anuais.

\subsection{Comparando-se dados secundários}

Nos dados apresentados na pesquisa da Printer.com (2009), verifica-se os resultados levantados de TP a mesma tendência dos valores lá produzidos, alocando a Century Gothic 10 como a mais eficiente na maximização do uso de tinta e toner - mesmo havendo uma inversão da EV 10 com a TR 11. Tendo em vista que, no site, a diferença entre os valores da taxa de preenchimento da CG 10 e TR 11 são inferiores a $0,09 \%$, não foi surpresa a constatação de uma variabilidade de apenas $0,01 \%$ entre os mesmos tamanhos e tipos de fontes em análise, conforme demonstrado na Tabela 4. Quantidade pequena a ponto de se inferir que o menor erro inerente da metodologia possa alterar as qualificações efetuadas pelo estudo de caso da $\mathrm{CMBH}$. A proximidade dos valores acabou por corroborar com o estudo desenvolvido pela Printer.com, aumentando a certeza de que ambos produziram dados confiáveis.

Tabela 4 - Resultados de TP para os mesmos tipos e tamanhos de fontes da análise da Printer.com

\begin{tabular}{cccc}
\hline Fonte & Tamanho & Preenchimento & Variação $^{\mathbf{a}}$ \\
\hline \hline Century Gothic & 10 & $2,55 \%$ & 0 \\
Ecofont & 10 & $2,59 \%$ & 0,04 \\
Times New Roman & 11 & $2,56 \%$ & 0,01 \\
\hline
\end{tabular}

Fonte: Dados da pesquisa.

Nota: ${ }^{a}$ Comparando-se ao menor valor, $2,55 \%$ da Century Gothic.

Por fim, deve-se mencionar o fato que, embora se tenha produzido um estudo comparativo nesta seção, esta apenas surgiu com o intuito de se avaliar a acurácia de ambos os estudos, uma vez que se espera uma mesma tendência dos valores dos dois. Portanto, de forma a evitar uma possível confusão do leitor, destaca-se que, no estudo de caso da $\mathrm{CMBH}$, por motivos previamente demonstrados, a comparação entre as fontes se deu entre a CG 11, a EV 10 e a TR 12, escalas diferentes das utilizadas pelo site.

\subsubsection{Consumo de folhas para impressão}

Uma vez que o consumo de papel varia conforme o tipo de letra e tamanho escolhido, também se mostra necessário uma análise referente à quantidade de papel utilizado por cada fonte em foco. Nesse contexto, a $\mathrm{CMBH}$ possui um gasto anual de folhas para impressão de mais de um milhão de folhas A4 utilizadas, totalizando um total de $\mathrm{R} \$ 19.373,87$, no ano de 2011. Todo esse consumo está atrelado a um descarte de mais de 
$4700 \mathrm{~kg}$ de papel $^{2}$, tanto como uma produção de 3,965 toneladas de gás carbônico. Uma vez que cada 80 gramas de papel produzidas demandam 10 litros de água, em média ${ }^{3}$, por parte do produtor, a CMBH consome indiretamente 594.750 litros anuais de água apenas com a aquisição de folhas para impressão (WATER FOOTPRINT NETWORK, 2011).

Dentre as várias fontes e tamanhos pesquisados, a Ecofont Vera Sans 10 figura como a mais econômica, ao se utilizar a Times New Roman 12 como mérito comparativo. Conforme sinalizado na Tabela 4, tanto o seu valor de NT como EU são melhores que as demais, resultando em um aproveitamento maior do espaço total da folha. A diferença é sutil de $4,6 \%$ de queda do valor de EU entre a TR 12 e a EV 10, resultando em um impacto redutivo de cerca de $\mathrm{R} \$ 891,00$ anuais, como demonstrado na Tabela 5. Ainda que pouco, quando comparado ao montante total para a aquisição desses itens, a mesma revela que esse resulta em uma isenção final do uso indireto de cerca de 27000 litros de água anuais e 0,18 toneladas de $\mathrm{CO}_{2}{ }^{4}$, além da redução de cerca de 54000 folhas A4 para impressão, representando $216 \mathrm{~kg}$. Tendo em vista que uma pessoa em média consome 5400 litros por mês de água (FUNDAÇÃO PROCON SÃO PAULO, 2012), 27000 litros seriam suficientes para o consumo ininterrupto da mesma por cinco meses seguidos.

Tabela 5 - Comparativo dos indicadores NT e EU para as fontes escolhidas

\begin{tabular}{ccccc}
\hline Fonte & Tamanho & NT & EU $^{\mathbf{a}}$ & Variação $^{\mathbf{b}^{2}}$ \\
\hline \hline Times New Roman & 12 & 3950 & 0,0938 & $0 \%$ \\
Ecofont Vera Sans & 10 & 4140 & 0,0895 & $-4,60 \%$ \\
Century Gothic & 11 & 2856 & 0,1297 & $38,27 \%$ \\
\hline
\end{tabular}

Fonte: Dados da pesquisa.

Nota: ${ }^{a}$ Valores dados em $\mathrm{cm}^{2}$.

${ }^{\mathrm{b}} \mathrm{A}$ variação foi calculada de acordo com os valores de Eu da TR 12.

A escolha de outra fonte e/ou tamanho - lembrando-se que a TR em menores escalas do que a 12 não são levadas em conta - acabaria por acarretar em um acréscimo do uso de papéis para impressões, estando esse crescimento condicionado tanto ao tipo como escala de cada fonte escolhida. Explicitado nas Tabelas 5 e 6, no uso da Century Gothic 11 esse aumento do valor de EU se verificaria em 38,27\%, implicando em um aumento dos gastos totais de $R \$ 7.414,38$, além de um uso indireto de mais 225.000 litros de água anuais e 1,51 toneladas de gás carbônico.

Tabela 6 - Resumo dos resultados anuais para consumo de papel para os tipos de fontes escolhidas

\footnotetext{
${ }^{2}$ Para este cálculo, fez-se a pesagem de uma folha A4 em uma balança de alta precisão, presente na Seção de Serviços Gerais (SecSer), obtendo um valor de 0,004 grama por folha. Ambos os tipos de papel, reciclável e branco, apresentaram os mesmos resultados.

3 É analisado todo o processo gerador do produto, a fim de se avaliar a quantidade de água necessária para a produção final de um bem. Este indicador é conhecido como Pegada de Água - Water Footprint - e é dado em litros.

4 O cálculo da massa de $\mathrm{CO} 2$ referente a utilização do total de folhas pela CMBH foi calculada através da Calculadora do aquecimento: controle suas emissões de CO2, disponível no site da Revista Veja: <http://veja.abril.com.br/complementos-materias/calculadora-aquecimento/info-popup.shtml>. Acesso em: 23 fev. 2013.
} 


\begin{tabular}{|c|c|c|c|c|}
\hline $\begin{array}{l}\text { Tipo da fonte e } \\
\text { tamanho }\end{array}$ & $\begin{array}{l}\text { Consumo de água } \\
\text { indireto }^{\mathrm{a}}\end{array}$ & $\begin{array}{l}\text { Emissão indireta } \\
\text { de } \mathrm{CO}_{2}^{b}\end{array}$ & Custo (R\$) & $\begin{array}{l}\text { Uso de folhas } \\
\text { de papel }\end{array}$ \\
\hline Times New Roman 12 & 594.750 & 3,965 & $19.373,87$ & 1189500 \\
\hline Ecofont Vera Sans 10 & $567.391,50$ & 3,785 & $18.482,67$ & 1134783 \\
\hline Century Gothic 11 & $822.360,83$ & 5,475 & $26.788,25$ & 1644722 \\
\hline
\end{tabular}

Fonte: Dados da pesquisa.

Nota: ${ }^{a}$ Valor em litros.

${ }^{\mathrm{b}}$ Valor em toneladas.

\subsection{Comparando os resultados}

Após a análise conjunta dos dois norteadores deste estudo - o consumo de folhas para impressão e de cartuchos de tinta e toner -, verificou-se a excelência dos resultados da Ecofont Vera Sans 10, aliando um estilo compacto e limpo a uma grande economia de não só de suprimentos como de custos. Assim, recomenda-se a utilização da Ecofont Vera Sans como a fonte mais adequada para substituir a atual Times New Roman 12, na $\mathrm{CMBH}$. Caso a $\mathrm{CMBH}$ adote a Ecofont Vera Sans, serão economizados anualmente: 27.358,5 litros de água; 0,18 toneladas de dióxido de carbono $\left(\mathrm{CO}_{2}\right), 53.946,12$ folhas de papel A4, 38 cartuchos e $\mathrm{R} \$ 11.552,00$, o que permitirá uma redução considerável no uso de recursos naturais, materiais e financeiros.

No intuito de ampliar os resultados deste estudo, buscou-se mensurar os potenciais ganhos advindos da adoção da Ecofont por parte de todas as casas legislativas do Estado de Minas Gerais. Uma vez que essas organizações apresentam semelhantes processos de produção de documentos, a transposição dos dados da $\mathrm{CMBH}$ para as demais casas mostra-se plausível. Na estimativa, foram utilizadas aproximações lineares simples, tendo como base comparativa dados relativos ao número de servidores e aos recursos financeiros da $\mathrm{CMBH}$ e a população dos municípios mineiros. No caso da estimativa de economia para a Assembleia Legislativa do Estado de Minas Gerais, foram comparados os números de servidores desta Casa com a da $\mathrm{CMBH}$. Com o objetivo de facilitar a compreensão dos cálculos, a seguir serão apresentados dois exemplos

Primeiro exemplo: Estimativa de economia anual com base na população ${ }^{5}$

Câmara Municipal de Belo Horizonte $(\mathrm{CMBH})$ : população por habitante 2.395.785 e economia anual de $\mathrm{R} \$ 11.552,00$.

Câmara Municipal de Uberlândia: população por habitantes 613.815 e economia anual de 2.959,69.

Estimou-se a economia anual da Câmara Municipal de Uberlândia através da comparação entre a população desta cidade com a de Belo Horizonte e os gastos da CMBH. Uma vez que se mostrou inviável a

\footnotetext{
${ }^{5}$ Os cálculos foram realizados pelos autores deste artigo, tendo como base dados do Instituto Brasileiro de Geografia e Estatística (2012, 31 de Agosto).
} 
obtenção de dados relativos ao número de servidores de todas as câmaras municipais de Minas Gerais, optou-se por utilizar o número de habitantes das cidades como proxy para estimar a economia anual das casas legislativas mineiras.

Segundo exemplo: Estimativa de economia anual com base no número de servidores ${ }^{6}$

Câmara Municipal de Belo Horizonte $(\mathrm{CMBH})$ : número de servidores 1.004 e economia anual de $\mathrm{R} \$ 11.552,00$.

Assembléia Legislativa do Estado de Minas Gerais: número de servidores 3.621 e economia anual de $\mathrm{R} \$ 41.663,14$.

Estimou-se a economia anual da Assembléia Legislativa de Minas Gerais através da comparação entre o número de servidores dessa casa legislativa e a $\mathrm{CMBH}$.

A Tabela 7 apresenta a consolidação dos indicadores de economia de recursos naturais, financeiros e materiais no caso de adoção da Ecofont por parte de todas as casas legislativas mineiras. Além dos valores anuais, também foram calculados os valores acumulados em quatro anos, porque corresponde ao período de cada legislatura. Os números apresentados são bastante significativos, pois, em quatro anos, a economia de recursos corresponde a $\mathrm{R} \$ 549.606 ; 1.140$ cartuchos de impressão; e 1,3 milhão de litros de água e 2,5 milhões de folhas de papel. Além disso, a redução da emissão de dióxido de carbono seria reduzida em mais de 8,5 toneladas.

Tabela 7 - Consolidação dos indicadores de economia de recurso naturais, financeiros e materiais no caso de adoção da Ecofont Vera Sans por parte de todas as casas legislativas mineiras

\begin{tabular}{cccccc}
\hline Instituição & Custo (R\$) & Cartuchos & $\begin{array}{c}\text { Emissão CO2 } \\
\text { (ton) }\end{array}$ & Água (I) & Papel $^{\mathbf{b}}$ \\
\hline \hline CMBH & $11.552,00$ & 38 & 0,18 & 27.359 & 53.946 \\
Câmaras Municipais $^{\mathrm{a}}$ & $84.186,47$ & 110 & 1,31 & 199.378 & 393.138 \\
\hline
\end{tabular}

Fonte: Dados da pesquisa.

Nota: ${ }^{a}$ Os valores referentes as Câmaras Municipais não levam em conta a Câmara Municipal de Belo Horizonte

${ }^{b}$ Valor referente ao pacote de 500 folhas

\section{Considerações finais}

Esta pesquisa conseguiu comprovar a ecoeficiência da Ecofont, através dos seguintes indicadores anuais de redução para a Câmara Municipal de Belo Horizonte: $12,50 \%$ para consumo de cartucho de impressão e 4,60\% para uso de folhas de papel para impressão. Em números absolutos, tem-se a seguinte economia anual: 23.358 litros de água, 38 cartuchos de impressão, 53.946 folhas de papel e $\mathrm{R} \$ 11.522,00$ (onze mil, quinhentos e vinte e dois reais). Além disso, a emissão de

\footnotetext{
${ }^{6}$ Os cálculos foram realizados pelos autores deste artigo, tendo como base dados da Assembléia Legislativa de Minas Gerais. Disponível em <http://www.almg.gov.br/opencms/export/sites/default/acompanhe/prestacao_contas/despesa-compessoal/relatorios_trimestrais/arquivos/2012/despesa_pessoal_2012_04.pdf>. Acesso em: 23 fev. 2013.
} 
dióxido de carbono $\left(\mathrm{CO}_{2}\right)$ seria reduzida em 0,18 toneladas. No caso de todas as casas legislativas adotarem a Ecofont durante o período da legislatura que corresponde a quatro anos, os indicadores são ainda mais significativos, pois a economia de recursos corresponde a: $R \$ 549.606$; 1.140 cartuchos de impressão; 1,3 milhão de litros de água e 2,5 milhões de folhas de papel. Além disso, a redução da emissão de dióxido de carbono seria reduzida em mais de 8,5 toneladas.

Cabe aqui ressaltar que esta pesquisa, apesar de ter utilizado, em seu desenvolvimento, algumas suposições específicas da Câmara Municipal de Belo Horizonte e ter calculado os valores de redução por meio de dados próprios da organização, esta pode ser generalizada para outras organizações públicas ou privadas. As conjecturas, aqui efetuadas, facilmente poderiam ser transpostas para a grande maioria dos ambientes de trabalho, acarretando pequenas alterações no resultado final. Os indicadores de economia anual utilizados poderão ser utilizados por qualquer organização pública ou privada que utilizam a Times New Roman 12 como fonte default do Microsoft Word. Outras fontes padrão, conforme esperado, demandariam diferentes análises comparativas.

O intuito desse estudo é contribuir para o debate das práticas ecoeficientes nas organizações. É interessante notar que práticas muito simples e sem custos adicionais, como a adoção da Ecofont, uma vez devidamente estudadas e implantadas, podem causar impactos relevantes em uma organização. Qualquer ideia ou projeto novos, ao serem implantados, podem sofrer resistências iniciais por parte daqueles que serão afetados, sendo estas até salutares, pois colocam à prova o projeto desenvolvido sob o olhar daqueles que são os mais importantes, os seus beneficiários. Dessa forma, é importante vencer as resistências iniciais às práticas ecoeficientes, através de estudos bem fundamentados e trabalhos de educação para a sustentabilidade com os colaboradores, que incluam palestras, seminários, oficinas e cursos para não só informar, mas, também, mobilizar as pessoas em prol das práticas sustentáveis dentro da organização.

Finalizando, pode-se dizer que, embora as ameaças à sustentabilidade sejam muito sérias e complexas, uma alternativa para se trabalhar em prol da sustentabilidade é "pensar globalmente e agir localmente", como bem disse a escritora americana Hanzel Henderson (FILETO, 2008). Portanto, a adoção de uma prática ecoeficiente em um local de trabalho, como a Câmara Municipal de Belo Horizonte (CMBH), por exemplo, representa um bom começo para se promover a sustentabilidade organizacional. Assim, tendo em vista que esta pesquisa comprovou a ecoeficiência da Ecofont, recomenda-se que ela seja implantada na $\mathrm{CMBH}$ e em outras organizações públicas ou privadas. A adoção da Ecofont, acompanhada dos devidos trabalhos de educação para a sustentabilidade, mostra-se não só viável e vantajosa do ponto de vista da implantação, como parte de um esforço maior e contínuo de se criar uma cultura da sustentabilidade nas organizações. 


\section{Referências}

ABRAMOVAY, R. Procura-se a empresa do futuro. 2012. Disponível em: $<$ http://www.planetasustentavel.abril.com.br/blog/muito-alem-da-economiaverde/2012/12/19/procura-se-a-empresa-do-futuro/>. Acesso em: $23 \mathrm{fev}$. 2013.

ADVOCACIA GERAL DA UNIÃO (AGU). Ecofont. Disponível em: $\leq$ http://www.agu.gov.br/sistemas/site/PaginasInternas/Ecofont/ecofont.aspx>. Acesso em: 12 fev. 2012.

ASSEMBLÉIA LEGISLATIVA DE MINAS GERAIS. Demonstrativo de despesa com pessoal. 2012. Disponível em: <http://www.almg.gov.br/opencms/export/sites/default/acompanhe/prest acao_contas/despesa-compessoal/relatorios_trimestrais/arquivos/2012/despesa_pessoal_2012_04.p df>. Acesso em: 23 fev. 2013.

AVPSOFT. Apfill. Disponível em: < http://avpsoft.com/products/apfill/>. Acesso em: 25 maio 2012.

AVPSOFT. User's guide. Disponível em: <http://avpsoft.com/download/apfill users guide.pdf>. Acesso em: 3 jun. 2012.

BIDERMAN, R. et al. Guia de compras públicas sustentáveis: uso do poder de compra do governo para a promoção do desenvolvimento sustentável. 2. ed. 2008. Disponível em: <http://www.iclei.org/index.php?id=9311>. Acesso em: 7 ago. 2012.

CÂMARA MUNICIPAL DE BELO HORIZONTE. Relatório técnico: consumo de suprimentos geral de 2011. Belo Horizonte, 2012.

CALVACANTI, C. (Org.). Meio ambiente, desenvolvimento sustentável e políticas públicas. São Paulo: Cortez Editora; Fundação Joaquim Nabuco, s.d. apud MELO NETO, F. P.; BRENNAND, J. M. Empresas socialmente sustentáveis: o novo desafio da gestão moderna. Rio de Janeiro: Qualitymark, 2004.

DIAS, R. Gestão ambiental: responsabilidade social e sustentabilidade. 2. ed. São Paulo: Atlas, 2011.

ECOFONT. Impressão sustentável utilizando o software Ecofont. Disponível em: <http://www.ecofont.com/pt/produtos/verde/imprimir/impressao-sustentavelutilizando-o-software-ecofont.html>. Acesso em: 17 jul 2012.

ESTADÃO. Caderno Econômico. Brasil tem poucos servidores públicos, mas despesa é alta diz OCDE. Disponível em: $<$ http://economia.estadao.com.br/noticias/economia,brasil-tem-poucos-servidorespublicos-mas-despesa-e-alta-diz-ocde,19219,0.htm >. Acesso em: 19 abr. 2012.

FILETO, A. Cuide do seu bolso e do planeta já! Belo Horizonte: Câmara Municipal de Belo Horizonte, 2008. (Cartilha Didática). 
FUNDAÇÃO PROCON. Água consumida no estado de São Paulo. Disponível em <http://www.procon.sp.gov.br/texto.asp?id=681>. Acesso em: 1 fev. 2012.

GAITHER, N; FRAZIER, G. Administração da produção e operações. São Paulo: Thomson Learning, 2007.

INSTITUTO BRASILEIRO DE GEOGRÁFIA E ESTATÍSTICA (IBGE). População. Disponível em: $<$ http://www.ibge.gov.br/home/mapa site/mapa site.php\#populacao $>$. Acessado em: 25 set. 2012.

MELO NETO, F. P.; BRENNAND, J. M. Empresas socialmente sustentáveis: o novo desafio da gestão moderna. Rio de Janeiro: Qualitymark, 2004.

MUNCK, L. Sustentabilidade organizacional: uma análise a partir da institucionalização de práticas ecoeficientes. In: SIMPOI 2010 - Simpósio de Administração da Produção, Logística e Operações Internacionais, 2010, São Paulo. São Paulo: Fundação Getúlio Vargas, 2010. Disponível em: < http://www.simpoi.fgvsp.br/arquivo/2010/artigos/E2010 T00183 PCN58078.pdf>. Acesso em: 10 jun. 2011.

NAGANO, M. Falsificação de cartuchos. Revista Recicla Mais, São Paulo, v. $1,2000$.

OLIVEIRA, D. P. R. Administração de processos: conceitos, metodologia, práticas. 2. ed. São Paulo: Atlas, 2007.

ONG WWF. Relatório Planeta Vivo, 2010. Disponível em: <www.wwf.org.br/informacoes/?uNewsID=26162>. Acesso em: 14 mar. 2011.

PRICEWATERHOUSECOOPERS. Too late for two degrees? Low carbon economy index 2012. Novembro 2012. Disponível em: $<$ http://www.pwc.com/en GX/gx/low-carbon-economy-index/assets/pwc-low-carboneconomy-index-2012.pdf > . Acesso em: 23 fev. 2013.

NITROPDF SOFTWARE. PrimoPDF. Disponível em: <http://www.primopdf.com/>. Acesso em: 6 jun. 2012.

PRINTER.COM. About us. Disponível em: <http://www.printer.com/about.us.html>. Acesso em: 18 jul. 2012.

PRINTER.COM. Printing costs: does font choice make a difference? Disponível em: <http://blog.printer.com/2009/04/printing-costs-does-font-choicemake-a-difference/> . Acesso em: 18 jul. 2012.

REVISTA VEJA. Calculadora do aquecimento: controle suas emissões de $\mathrm{CO}_{2}$. Disponível em <http://veja.abril.com.br/noticia/brasil/aquecimento-controlesuas-emissoes-co2>. Acesso em: 18 jul 2012.

RIZTMAN, L; KRAJEWSKI, L. J. Administração da produção e operações. São Paulo: Pearson Prentice Hall, 2004.

SARAMAGO, J. Caim. São Paulo: Companhia de Letras, 2009. 
SAVITZ, A. W.; WEBER, K. apud MUNCK, L. Sustentabilidade organizacional: uma análise a partir da institucionalização de práticas ecoeficientes. In: SIMPOI 2010 - Simpósio de Administração da Produção, Logística e Operações Internacionais, 2010, São Paulo. São Paulo: Fundação Getúlio Vargas, 2010. Disponível em: <http://www.simpoi.fgvsp.br/arquivo/2010/artigos/E2010 T00183 PCN58078.pdf>. Acesso em: 10 jun. 2011.

SLACK, N; CHAMBERS, S; JOHNSTON, R. Administração da produção. 3. ed. São Paulo: Atlas, 2009.

SUKHDEV, P. Corporation 2020: transforming business for tomorrow's world. Washington DC: Island Press, 2012.

TIPOGRAFOS.NET. Times New Roman 1932. Disponível em: <http://tipografos.net/tipos/times.html>. Acesso em: 17 jul. 2012.

YIN, R. K. Estudo de caso: planejamento e métodos. 3. ed. Porto Alegre: Bookman, 2005.

WATER FOOTPRINT NETWORK. The water footprint assessment manual: setting the global standart. Disponível em: $<$ http://www.waterfootprint.org/?page=files/WaterFootprintAssessmentManual $>$. Acessado em: 17 jan. 2012. 